\title{
Children with Specific Language Impairment (SLI) Need Qualitatively Enriched Interactions to Successfully Partake in Mathematics Education
}

\author{
Anja Schröder, Ute Ritterfeld \\ TU Dortmund University, Germany
}

\begin{abstract}
Recent studies reveal that a subgroup of children with SLI display difficulties in early arithmetic skills which are often persisting several school years. This paper argues that these children are in need for qualitatively enriched interactions with their teachers in order to successfully partake in mathematical conversations. We hereby built on the assumption that especially teacher-student interactions are promoting mathematical learning. By asking questions and setting specific impulses teachers are able to provide the required interactional scaffolding. Furthermore, in adapting their interactive behavior closely to the students, abilities they enable them to participate in mathematics instruction. At TU Dortmund University we launched a research project with the goal to investigate interactions between children with SLI and their mathematics teachers to obtain insights into how these children learn to successfully take part in interactions and hereby develop their mathematical knowledge. This paper first outlines the rationale for our approach and describes the first step for empirical investigation, namely the development of the coding system to conduct a content analysis of scaffolding behavior in teacher-student interactions. The code system is guided by a combined deductive-inductive approach. The inductive strand builds on videotaped interactions between mathematics teachers and children with SLI within primary education.
\end{abstract}

\section{Introduction}

Children with specific language impairment (SLI) not only suffer from language barriers but also experience consequences in their mathematical learning as recent studies demonstrate [1]. Specifically, children with SLI often show lower proficiencies in various arithmetic skill areas compared to their age matched peers, for example in verbal counting, number words and the correct number word sequence, rote retrieval of memorized basic fact families (i.e., 5+2=7), written calculations, advanced strategies use, and a prolonged use of counting strategies [1]. With the term mathematical skills we specifically understand arithmetic skills.

Based on longitudinal observations by Fazio it is evident that difficulties in arithmetic skills do not emerge in higher grades but are already rooted in preschool age [2]. Deficits in basic number skills even gradually proceed over school years.

In addition to the association of severity in SLI and mathematical skills studies also reveal that higher language abilities are closely associated with the evolvement of mathematical skills [3].

Since mathematic deficits of children with SLI accumulate over school years language impairment poses as key developmental inhibitor for the acquisition of first, basic mathematical skills, and further as an ongoing barrier for more complex developmental milestones.

Such close association between mathematical learning and language abilities becomes more obvious as all mathematical education requires social interactions in the classroom which are in turn mainly language based. However, to date mathematics didactics have not yet been specifically adapted for children with SLI. Our goal is to bridge this gap with a combined deductive- inductive strategy to obtain insight into structures and mechanisms of teachers' scaffolding techniques.

Our deductive approach is guided by knowledge from two rather unrelated disciplines: Speechlanguage pathology and mathematics education. First, specific challenges in acquiring basic arithmetic competencies for children with SLI need to be identified. Second, demands of mathematic didactics need to be addressed. In combining these theoretical strands we propose an enriched linguistic approach exemplifying scaffolding techniques to specifically support the acquisition of mathematical concepts.

Two ways to illuminate the challenges of mathematical learning are brought into account: First, difficulties shown particularly in children with language impairments and second, verbal 
demands brought along with mathematical learning. We start with a brief research summary of available evidence on mathematical learning in children with SLI and then elaborate on our perspective on the connection between mathematical learning and interactive skills. Finally, we conclude with a short description of our inductively generated coding system that will be used for an elaborate content analysis of scaffolding behavior in teacher-student interactions.

\section{Challenges of mathematical learning for children with SLI}

The International Classification of Diseases (ICD 10, F. 80) defines specific developmental disorders of speech and language as "Disorders in which normal patterns of language acquisition are disturbed from the early stages of development. The conditions are not directly attributable to neurological or speech mechanism abnormalities, sensory impairments, mental retardation, or environmental factors. Specific developmental disorders of speech and language are often followed by associated problems, such as difficulties in reading and spelling (...)" [4]. Note that this definition does not mention mathematics although recent studies demonstrate the association of SLI with deficits in mathematical learning in many children [2] [3].

It is yet not fully understood why some children with SLI do suffer from mathematical difficulties and others do not. Possibly, only a subgroup of children with SLI is affected [5]. We therefore propose a 2-by-2 grid that combines arithmetical and linguistic learning to exhibit the four possible subgroups of children either displaying rather poor or rather advanced arithmetic skills and rather poor or rather advanced linguistic skills:

1. One group with difficulties in linguistic learning (e.g., children with SLI) and ordinary arithmetic skills,

2. a second group with difficulties in linguistic learning (SLI) and difficulties in arithmetic skills

3. a third group with ordinary language development and ordinary arithmetic skills (not further mentioned in this article)

4. a fourth group with ordinary language development and difficulties in arithmetic learning.

Table 1. Subgroups of children depending on their arithmetical and linguistic skills

\begin{tabular}{|c|l|c|}
\hline & $\begin{array}{l}\text { Difficulties in } \\
\text { language } \\
\text { development, } \\
\text { e.g. SLI }\end{array}$ & $\begin{array}{l}\text { Typical language } \\
\text { development }\end{array}$ \\
\hline $\begin{array}{c}\text { Typical } \\
\text { arithmetic } \\
\text { skills }\end{array}$ & $\begin{array}{l}\text { Children with } \\
\text { SLI and typical } \\
\text { arithmetic skills }\end{array}$ & $\begin{array}{c}\text { Children with } \\
\text { typical language } \\
\text { development and } \\
\text { typical arithmetic } \\
\text { skills Children with }\end{array}$ \\
\hline
\end{tabular}

\begin{tabular}{|c|c|c|}
\hline & & $\begin{array}{c}\text { typical language } \\
\text { development and } \\
\text { typical arithmetic } \\
\text { skills }\end{array}$ \\
\hline $\begin{array}{c}\text { Difficulties } \\
\text { in } \\
\text { arithmetic } \\
\text { skills }\end{array}$ & $\begin{array}{c}\text { Children with } \\
\text { SLI and } \\
\text { difficulties in } \\
\text { arithmetic skills }\end{array}$ & $\begin{array}{c}\text { Children with } \\
\text { typical language } \\
\text { development and } \\
\text { difficulties in } \\
\text { arithemtic skills }\end{array}$ \\
\hline
\end{tabular}

In the following we focus on the two subgroups of children with SLI. Especially the subgroup of children with combined linguistic and arithmetic deficits poses a tremendous challenge for mathematic education as every teaching is language based. In order to better understand the complex interdependencies of the two domains we will elaborate the theoretical explanations discussed in the literature.

\subsection{Determinants for arithmetic skills}

A longitudinal study of Durkin et al. indicates that severity in SLI is closely related to mathematical deficits [3]. The authors demonstrated that those children with SLI who progressed less in their language compared to their peers within one school year also advanced less in their mathematical skills. At the same token, children with SLI who substantially progressed in language demonstrated better mathematical skills. Taken together, mathematical deficits of some children with SLI emerge in early school years and accumulate with time. In these cases the language impairment might be considered a causal barrier for the acquisition of first, basic arithmetic skills and later, more complex arithmetic skills.

However, language competencies are clearly not the only possible influence on arithmetic learning as some children without language barriers suffer from arithmetic deficits. Also, some children with SLI demonstrate adequate arithmetic skills. In accordance with the literature Ritterfeld et al. conclude that at least two factors influence arithmetic learning: linguistic competencies and the capacity of the working memory, especially the phonological loop [6].

\subsection{Linguistic skills as determinants for arithmetic skills}

Based on her acquisition model of early basic arithmetic skills Krajewski does not consider linguistic competences necessary at all stages of acquisition [7]. The influence of linguistic competencies is supposed to vary throughout the acquisition process. While early perception of quantities is inherently visual and infants can identify them long before their acquisition of the first words, the precise concept of quantities, the acquisition of cardinal number sense as well as the 
description of differences between quantities by using number words seems to be closely linked to language. In the latter case it is required to use linguistic knowledge about number words for representation of quantities in memory and for the description of manipulated quantities with concrete numbers.

In principal language could influence mathematical learning in two different ways: First, language might provide the precondition for the development of number concepts because it contributes to a symbolic cognition which in turn is necessary for the development of number concept [8]. The second possible direction of influence is indirect. One can argue that language is not causatively responsible for the construction of knowledge about quantities but can facilitate the construction of the precise quantity concept [9].

\subsection{Phonological information processing as determinant for arithmetic skills}

As illustrated in Table 1 we can identify two subgroups of children with SLI, one with deficits in arithmetical learning one without such deficits. . Both subgroups nurture the assumption that linguistic deficits cannot sufficiently explain arithmetical deficits. Consequently, other factors than language constrain mathematics learning that need to be considered to fully understand the difficulties of children with SLI in arithmetic learning.

Various studies reveal that working memory and precursor skills are the most relevant factors for arithmetic development [10]. Especially the phonological loop as part of the working memory seems to be of high relevance for the acquisition of early arithmetic skills [11].

Children with SLI suffer from a constraint in the capacity of the phonological loop [12]. This constraint not only poses a barrier for language learning but most likely also for mathematical learning. Röhm et al. recently provided evidence that the effect of language on arithmetic skills is mediated through the capacity of the phonological loop [13]. The authors also confirm the direct influence of the phonological loop on arithmetic skills. Ritterfeld et al. proposed the so called third factor hypothesis in accounting for the effect of working memory - especially the phonological loop - in the interplay of linguistic and mathematic skills [6].

Having a closer look on the specific symptoms children with SLI display in mathematics, it becomes obvious that they have difficulties in the acquisition of number words, the rote retrieval of memorized basic facts like simple calculations, and the use of advanced calculation strategies [2]. We argue that these findings may be explained with regard to the phonological information process as a whole. While the working memory plays an essential part in this process, it is not sufficient to merely consider the phonological loop. The following components must be taken into account as well: the phonological awareness that particularly influences the early number word acquisition, the phonological loop, and the retrieval process from long term memory [10] [14]. Children with SLI are known to have deficits in all three components of the phonological information processing [16].

The theoretical relation between these three components (phonological input processing, storing and output generation) may be deduced from the information processing procedure during solving an arithmetical problem like counting. For example, to count three elements a child hears number words spoken by another person while counting. S/he has to parse the phonological structure of the number words, keep it in the phonological loop, and compare it with versions of the used number words already stored in his/her long term memory. Long term storage does not only entail knowledge of the word form but does also include semantic information, in the example given representations about concepts of quantities. As children with SLI exhibit deficits in their phonological awareness abilities and a lower capacity of the phonological loop compared to typically developed peers difficulties in learning the number words sequence may be the result [15].

According to Stackhouse and Wells, a child needs to retrieve the word form from his/her long term memory simultaneously to activating his/her semantic representation when s/he wants to speak a number word [16]. As children with SLI suffer from difficulties in retrieval of word forms they might not be able to access a number word although they may have stored them and even their sequence [15].

To better understand the relation between storing, i.e. the ability to keep information in mind for a short time, and processing, i.e. analyzing language to generate linguistic representations, we refer to a functional model of working memory proposed by Montgomery [12]. The model emphasizes the trade-off between storing and processing information when solving a challenging task that overexerts the available resources.

\section{Perspective on mathematics learning}

Even in the didactic of mathematics it gains more and more acceptance that mathematical learning could never be achieved without application of language [17]. Consequently, some authors propose that language learning is inherent in mathematical education and therefore language concepts should be included in any mathematics instruction. However, to date these concepts have been focusing on second language learners exclusively. Considering working memory and 
phonological information processing as mentioned above has not yet been elaborated for the special needs of children with SLI.

Steinbring and Nührenbörger conceptualize mathematical learning within the framework of enculturation [17]. Culture of mathematical education is hereby conceptualized as a process in which mathematical meanings are negotiated via communication. The authors implicitly refer to two linguistic levels: With the construction of meaning they refer to a semantic level and with the communicative element on the pragmatic resp. the discourse level. Both of these levels could function as a barrier for mathematical learning of children with SLI. Hence it is worthwhile to have a closer look on each of them.

\subsection{Particularity of mathematical terms (semantic level)}

As all acquisition arithmetic learning is understood as an active, constructional process of the learner. That means that in the examination of an arithmetical problem or structure the learner constitutes his own meaning of the problem. For example, while learning to count a child has to find out that number words like "three" are not a feature of the counted item but an attributed element. Anything that is countable could be named "three". We reason that mathematical terms are different from everyday words in not representing objects but being signs from the very beginning of being introduced. In addition, to representing (verbal and written) signs mathematical terms also mediate to the context in which they are used. This referential context consists of a particular problem or task, like wanting to know who has won the most coins in a play or calculating $3+5$. Mathematical terms are represented by the signs belonging to them like the number word three. The signs have both, a semiotic function because they signify something, and an epistemological function, because the way of making use of them is a manifestation of the user's construction of knowledge. The number three is not identical to the objects but defined by its position in the number word sequence and the relation to other numbers and quantities. Mathematical knowledge therefore refers to abstract relations, structures, and pattern [18].

Taken together, there are three entities that constitute the mathematical term: the referential context, the signs, and the mathematical term itself. Steinbring illustrated them with the so called epistemological triangle [18].

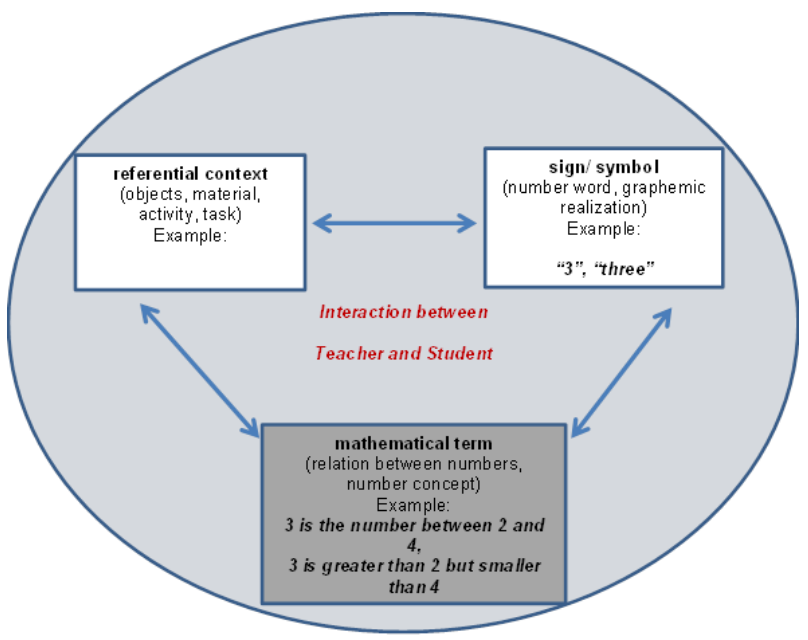

Figure 1. Epistemological triangle [in
adaptation of Steinbring, 18]

\subsection{Mathematical learning in social interactions (pragmatic/discourse level)}

Any attempt to solve a new substantially arithmetic problem is embedded in social interactions. For example, children only learn to count because they experience other people counting and hereby explore the social sense of counting, i.e. identifying quantity. Social interactions are considered an access to the child's thoughts and his/her conceptual knowledge [17] [18]. Verbal interactions require linguistic skills in order to negotiate meaning, to extend and reconstruct knowledge. Language does not only reflect acquired but influences the construction of new knowledge and also channels further learning. Consequently, the teachers' interactive support is of utmost importance in a child's acquisition of knowledge [19]. For mathematical skills a teacher can apply different strategies to support a student: By setting impulses a teacher prompts the student to consider aspects of the mathematical discourse that s/he would not have recognized on his/her own. For example the teacher asks the student to describe his/her method of problem solving after having given a correct answer. The student is hereby prompted to further reflect on his or her chosen solution.

The mathematical discourse develops in the dialogue of teacher and student. Mathematical knowledge is hereby co-constructed. Apart from that negotiation processes about the individual constructions of meanings of specific signs and symbols take place. That implies which conceptual knowledge is available for each of the participants of the interaction. The pragmatic impulses of the teacher are the control mechanism by which this coconstruction enables advancement and reorganization of knowledge [19].

Hence, a teachers' interactive support has two main functions: first, to secure a successful 
interaction process and second, to utilize this interaction process for mathematics education. As a consequence, teacher-student interactions may be considered the motor of acquisition processes extending the mathematical knowledge.

Taking this interactive perspective alters our view of the process of mathematical learning: Such processes become even apparent in the increasingly competent participation of a student in class interactions and in the co-construction of the interactive structure between teacher and pupil. Mathematical learning can (only) take place when the interaction process is successful [20].

With respect to the content of what a student has to learn in order to successfully take part in mathematical conversations, we propose that not only mathematical knowledge is essential. In addition to the acquired knowledge interactive and linguistic skills are required to successfully take part in the mathematical discourse relevant to develop the desired arithmetic skills.

We conclude that children with SLI are confronted with at least three barriers while learning arithmetics: pronounced difficulties in (1) the acquisition of linguistic skills, (2) phonological information processing and (3) in interactive resp. discourse capabilities [21].

In general, developmental barriers may result from external or internal factors. While internal mechanisms of acquisition cannot be influenced directly, the teachers' interactive support may make a difference. These interactions provide the context in which the student activates constructs or extends his/her mental representations of the mathematical problem. As this context follows an intentional didactic chosen and established by the teacher it provides specific demands and stimulations for the student. Ideally, they are based upon a teacher's observation of the student's abilities. With this line of argumentation we pledge for a didactical approach in which access to the learning child is established through appropriate interactions. Such interactions may be considered medium bridge between the inner world of the child and the external world of social and subject-specific requirements in school based learning [19].

\section{Identifying successful interactive scaffolding}

Given that interactions are proposed as the pathway to help children with SLI learn arithmetics we established an empirical framework in order to identify successful interactive strategies. A first step of this approach makes use of teachers' experiences in the class room. We hereby attempt to identify teacher' strategies in interaction with those children who display language barriers that work.

\section{Development of coding system}

\subsection{Proposed methodology}

Teachers' use of interactive scaffolding within the context of mathematics education should be observed and analyzed. Analysis of video captured material should make use of a coding system that allows for identification of theory deducted scaffolding techniques as well as for inductive exploration. For the latter interactions between special education teachers trained in language impairment as well as mathematics education and their students were exploited. As some strategies and mechanisms used in interactions might be intuitive and unconscious to the teachers we concluded that they are not accessible upon reflections. Thus, observation was given priority over interviewing.

\subsection{Deductive approach}

Deduced form the theoretical insights introduced above we attempt to identify teacher's behavior with respect to three dimensions:

- Dimension of the linguistic-interactive requirements and their supportive function

- Didactic dimension, i.e. the referential context

- Dimension of mathematical knowledge resp. acquisition.

The relevance of the linguistic-interactive dimension is seen in its key part in arithmetic development. To assess the usage and adaption of impulses to the specific need of individual students we developed codes that consider the level of complexity that is inherent in any impulse or question. One code allows for the frame of reference the verbal impulse is connected with. That means that we observe if the verbal impulse refers to a real object resp. material or if the verbal impulse refers to thoughts and reflections [23]. A further code considers the scope that is opened up for the student to unfold his/ her own ideas and thoughts by a specific impulse. We distinguish between direct and indirect impulses [24]. Direct impulses are more supportive because they constrain the variety of options to answer and therefore effect as intensive guidance of the student. Indirect impulses in contrast function as a thinking aid, which means that they open up a wider scope of action and offer less support by delivering fewer contents.

Additionally we set the interactive function of an impulse, question or request to find out to what extend the individual impulse contribute to the process of interaction and simultaneously to the solution of the mathematical problem.

The didactic dimension is of relevance because depending on the task format the interactive structure may vary. The task format provides an 
insight into the didactic situation in which the interaction is embedded and hereby indicates which communicative function is expected. Closed formats are rather directive and entail a fixed solution. The task should be solved by the collectively compiled procedure of solution. The function of the interaction lies here in the recapitalization of prior acquired knowledge. Open formats do not determine the solution pathway. They may be chosen from collectively compiled or self-generated procedures of solutions. Teacherstudent interactions are functional to introduce or prompt possible solution pathways.

Finally, the mathematical dimension emphasizes the acquisition level of the focused arithmetic content. We are hereby building on the acquisition models proposed by Krajewski and Fritz and Ricken [7] [22]. With the analysis we aim to capture the aspiration level of the interactions. Supposedly, cognitive capacity of a child is already limited if the mathematical content itself is cognitively demanding. In this case capacity would no longer be sufficient for an elaborative and independent construction of the interaction. Consequently, we expect that students need less advanced impulse to successfully take part in interactions.

For analyzing these dimensions we distinguish three different units of analysis. To analyze arithmetic vocabulary, the benchmark to which a question or request refers or the level of requirement of an impulse every single utterance is focused. But to investigate the interactional function or the level of requirements of teachers' impulses a single utterance is not sufficient so that adjacent utterances or turns must be considered as well. For example to interpret the interactional function of an utterance as affirmation it is necessary to regard what is said before and what is the reaction of the partner in interaction. The level of requirements of an impulse is defined by the inherent requirement of the impulse and additional application of materials or gestures.

The whole interactive episode is the focused unit of analysis when the discourse function of an impulse is to be assessed. Discourses and conversations in schools basically contain a certain structure that can be described by different jobs teachers and students have to fulfill in order to constitute a complete conversation structure. These jobs are not identical to single utterances or turns, but can be created by varied utterance or turns of one or more participants. So they are utterancespanning. One job for example is the explanation for the solution. So if the student does not deliver him-/herself this explanation the teacher has to ask for it. So by asking the teacher contributes to the fulfillment of this job. The student may deliver an incomplete answer, so he/she takes part in the fulfillment of the job, but not sufficiently, so that the teacher has to ask again and so on. So the different turns of the teacher and the student are like pieces in the puzzle that in sum complete the job. Which jobs are processed can only be deduced by the complete interactive episode.

\subsection{Inductive approach}

5.3.1. Data collection Five special education schools for children with language disorders in the state of Northrhine-Westfalia, Germany, were asked to take part in the project - three of them agreed. In each school one teacher of a first grade class participated in the study. Different interactional situations should be observed: situations in which the conversation is established between the teacher and the whole class and a second one in which the teacher involves particular students in a mathematical conversation. For the latter case in each class three pupils were chosen who represented prototypical examples for language barriers within this school type: one child with SLI, one child with non-specific language impairment and learning disabilities (LI), and one bilingual child with non-specific language impairment but no learning disabilities (BIL).

Classroom interactions during mathematic lessons within a period of seven weeks were fully videotaped. A total of 53 math lessons were assembled. Selected units for analyses contained all interactions of the teacher with the three chosen children either in face-to-face or in group interactions.

5.3.2. Data preparation In order to select suitable parts of the video data for analysis we distinguished two phases in the mathematical lessons characterized by the interactional situation: (1) the teacher's introduction to a specific task or problem while addressing the whole class (elaboration phase). (2) A teacher approaching a single child individually to help him/her work on his or her own task (working phase). Every videotaped lesson was segmented into these two phases as selection unit. For unit of analyses each phase was then segmented into interaction episodes. Interaction episodes were defined as revolving around one singular theme, centering around one specific task, and using one set of material only. A new episode begins if either the task or the material was changed, a new question was asked by the teacher or the teacher was summarizing.

Selected episodes were subsequently analyzed with the following three epistemic questions: 1) Which kind of impulses does a teacher use to involve a child with SLI compared to a child with non-specific language impairment and learning disabilities (LI)? 2) In which way are illustrations and materials used in the interactions with a child with SLI? 3) How does a teacher reach consent with the child in the construction of meaning of a mathematical concept?

Specifically, we were looking at verbal scaffolding, gestures, usage of illustrations and 
supporting materials, and responses to misunderstandings in the interactions.

All material was exported into ELAN and coded by a total of three coders each addressing one of the above questions. Each coder was prompted

5.3.3. Inductively generated codes For generating codes from the empirical material we focused on the three dimensions introduced above:

- interactive dimension to assess the use of impulse in adaptation to the specific needs of individual students

- dimension of mathematical knowledge to assess the negotiation of meanings and the way of reaching consent

- didactic dimension to assess the usage of materials and illustrations

With the linguistic dimension we consider the requirements inherent in the teachers' interactive impulses or questions. By using materials, real objects or gestures the level of interactive requirement could be modified. The use of these different semiotic systems could facilitate verbal comprehension, because the meaning could be derived by language and additionally by further semiotic systems. Furthermore the use of additional semiotic systems could extend the meaning of a mathematical problem that is verbally introduced. So we ascertain for each impulse or question the individual level of requirement.

With regard to the dimension of mathematical knowledge we developed a code to assess the construction of meaning. We assess adjacent utterances of teacher and student that either contain a collective consent or a dissent. Basis for this code is, if teacher and student seem to focus on the same arithmetical concept. Indicators for dissent are different use of symbols or arithmetical terms, false results and unresolved problems or misunderstandings.

The usage of materials and illustrations is categorized in the use of real objects, illustrations and graphics and symbols or signs. To observe the use of these three types of material in interaction with children with different needs different levels of requirements combined with that material are acquired.

Table 2. Dimensions of coding categories

\begin{tabular}{|l|l|l|l|}
\hline $\begin{array}{l}\text { Unit of } \\
\text { analysis }\end{array}$ & $\begin{array}{l}\text { Dimension of } \\
\text { linguistic- } \\
\text { interactive } \\
\text { requirements }\end{array}$ & $\begin{array}{l}\text { didactic } \\
\text { dimensi } \\
\text { on }\end{array}$ & $\begin{array}{l}\text { Dimension } \\
\text { of } \\
\text { mathemati } \\
\text { cal } \\
\text { knowledge/ } \\
\text { acquisition }\end{array}$ \\
\hline $\begin{array}{l}\text { utteran- } \\
\text { ce/turn }\end{array}$ & $\begin{array}{l}\text { Frame of } \\
\text { reference for } \\
\text { verbal impulses } \\
\text { (real object vs. } \\
\text { thoughts or } \\
\text { reflections), }\end{array}$ & & \\
\hline
\end{tabular}

\begin{tabular}{|c|c|c|c|}
\hline & $\begin{array}{l}\text { kind of gestures, } \\
\text { level of cognitive } \\
\text { abstraction } \\
\text { addressed by } \\
\text { the material, } \\
\text { key words used } \\
\text { from a stated } \\
\text { mathematical } \\
\text { vocabulary, }\end{array}$ & & \\
\hline $\begin{array}{l}\text { across } \\
\text { turns }\end{array}$ & $\begin{array}{l}\text { level of } \\
\text { interactive } \\
\text { requirements of } \\
\text { impulses, } \\
\text { interactive } \\
\text { function of } \\
\text { impulses, } \\
\text { combination of } \\
\text { semiotic systems }\end{array}$ & $\begin{array}{l}\text { didactic } \\
\text { function } \\
\text { of } \\
\text { impulse, } \\
\text { level of } \\
\text { requirem } \\
\text { ents } \\
\text { inherent } \\
\text { in } \\
\text { material, }\end{array}$ & \\
\hline $\begin{array}{l}\text { inter- } \\
\text { active } \\
\text { episode }\end{array}$ & $\begin{array}{l}\text { jobs of } \\
\text { discourse/ } \\
\text { conversation } \\
\text { structure, }\end{array}$ & $\begin{array}{l}\text { kind of } \\
\text { tasks, }\end{array}$ & $\begin{array}{l}\text { level of } \\
\text { mathemati- } \\
\text { cal } \\
\text { acquisition } \\
\text { required to } \\
\text { solve or } \\
\text { elaborate } \\
\text { the } \\
\text { mathemati- } \\
\text { cal problem, } \\
\text { construction } \\
\text { of meaning }\end{array}$ \\
\hline
\end{tabular}

Table 2 summarizes the coding dimensions by three distinguishable unit of analyses (utterance/turn/interactive episode) in order to identify patterns of interactive scaffolding in the teachers impulses.

\section{Conclusions}

The presented approach was successful in delivering a systematic code book for data analyses of teacher-child interactions with an emphasis on scaffolding strategies in primary mathematics education with language impaired children. The emphasis of the coding system lies on the interconnection between interactive structure and mathematical learning. The coding system will be applied to the available data base of 53 hours video material. Analysis will allow for identification of specific interactive scaffolding strategies for children with SLI as well as more general strategies exemplified to all children with learning barriers.

\section{Acknowledgements}

We would like to thank all participating teachers for consenting into us videotaping their lessons as well as to the participating families. Furthermore, we are grateful to the German School District 
Government of Münster and Arnsberg for their friendly support.

We also thank Lena Gantenberg, Miriam Kleinschmid, and Theresa Funke for their contribution to the development of our coding system.

\section{References}

[1] A. Schröder, and U. Ritterfeld, „Zur Bedeutung sprachlicher Barrieren im Mathematikunterricht der Primarstufe: Wissenschaftlicher Erkenntnisstand und Reflexion in der (Förder-)Schulpraxis“, (Relevance of language barriers to primary mathematical education: academic level of knowledge and reflection of practical experiences in (special education) schools.) Forschung Sprache, dgs Sprachheilarbeit, 2014, pp. 49-69. DOI: $10.2443 / \mathrm{skv}-\mathrm{s}-2014-57020140104$

[2] B. B. Fazio, "Arithmetic calculation, short-term memory, and language performance in children with specific language impairment: A 5 year follow-up", Journal of Speech, Language, and Hearing Research, 42, 1999, pp. 420-431

[3] K. Durkin, P. L. H. Mok, and G. Conti-Ramsden, "Severity of specific language impairment predicts delayed development in number skills", Frontiers in Psychology, 4, 2013, pp. 1-10.

[4] WHO „International Classification of Diseases and related Health Problems“, 10th revised version, 2010.

[5] R. Cowan "Language disorders, special needs and mathematics learning". In: S. Lerman (Ed.), Encyclopedia of mathematic education, Springer Science and Buisness Media, Dordrecht, 2014, pp. 336-338.

[6] U. Ritterfeld, A. Starke, A. Röhm, S. Latschinske, C. Wittich, and E. Moser Opitz, „Über welche Strategien verfügen Erstklässler mit Sprachstörungen beim Lösen mathematischer Aufgaben?"“, (Which strategies do first grade pupils with language impairment use to solve mathematical tasks?) Zeitschrift für Heilpädagogik, 4, 2013, pp.136-143.

[7] K. Krajewski, „Entwicklung und Förderung der vorschulischen Mengen-Zahlen-Kompetenzen und ihre Bedeutung für die mathematischen Schulleistungen“" (Development and fostering of early preschool quantitynumber competencies and their relevance for mathematical achievement in school), In G. SchulteKörne (Hrsg.), Legasthenie und Dyskalkulie: Aktuelle Entwicklungen in Wissenschaft, Schule und Gesellschaft, Winkler, Bochum, 2007, pp. 325-332

[8] H. Wiese, ,Sprachvermögen und Zahlbegriff - zur Rolle der Sprache für die Entwicklung numerischer Kognition" (Language competencies and number concept - the role fort he development of the numerical cognition) In P. Schneider, M. Wedell (Hrsg.), Grenzfälle. Transformationen von Bild, Schrift und Zahl VDG, Weimar, 2004, pp. 123-145

[9] R. Gelman, and B. Butterworth, "Number and Language: How are they related?" Trends in Cognitive Sciences, (9) 2005, pp. 6-10.
[10] K. Krajewski, G. Nieding, and W. Schneider, "Kurz- und langfristige Effekte mathematischer Frühförderung im Kindergarten durch das Programm 'Mengen, zählen, Zahlen'“" (shortterm and longterm effects on early mathematical fostering measures in Kindergarten by the programm „quantities, counting and numbers") Zeitschrift für Entwicklungspsychologie und Pädagogische Psychologie (40), 2007, pp. 135-146.

[11] A.-L. Preßler, K. Krajewski, and M. Hasselhorn „Working memory functioning in preschool children contributes to the acquisition of school relevant precursor skills", Learning and Individual Differences, (23), 2013, pp. 138-144.

[12] J. W. Montgomery „Working memory and comprehension in children with specific language impairment: what we know so far", Journal of communication disorders, (36), 2003, pp. 221-231.

[13] Röhm, A., Starke, A. and Ritterfeld, U. "Die Rolle von Arbeitsgedächtnis und Sprachkompetenz für den Erwerb mathematischer Basiskompetenzen im Vorschulalter" (The role of working memory and language competencies for the acquisition of basic mathematic skills in preschool age) (Zur Publikation eingereicht.)

[14] A. Mayer, „Spezifische Akzentuierung des Mathematik-Unterrichts bei sprachbehinderten Kindern" (particular accentuation of mathematic education with children with language disorders), In: Deutsche Gesellschaft für Sprachheilpädagogik (Hrsg.), Sprachheilpädagogischer Unterricht. Symposium zu Ehren des ehemaligen Bundesvorsitzenden Kurt Bielfeld, Edition von Freisleben, Würzburg, 2007, pp.28-46.

[15] A. Baddeley, "Working memory and language: An overview", Journal of Communication disorders (36), 2003, pp. 189-208.

[16] J. Stackhouse and W. Wells, Children's speech and literacy difficulties. A psychological framework, Whur, London, 2002.

[17] H. Steinbring and M. Nührenbörger, „Mathematisches Wissen als Gegenstand von Lehr-/ Lerninteraktionen. Eigenständige Schülerinteraktionen in Differenz $\mathrm{zu}$ Lehrerinterventionen"(mathematical knowledge as subject of learning-and teaching interactions. Autonomous student interactions in distinction from teacher interventions) In: DausendschönGay, U.; Domke, C. and Olhus, S. (Ed.), Wissen in (Inter-) Aktion. Verfahren der Wissensgenerierung in unterschiedlichen Praxisfeldern, De Gruyter, Berlin, 2010, pp. 161-188

[18] H. Steinbring „Mathematische Bedeutung als eine soziale Konstruktion - Grundzüge der epistemologisch orientierten mathematischen Interaktionsforschung “ (mathematical meaning as social construction - essentials of epistemologically orientated mathematic interaction research), Journal für Mathematik-Didaktik, 21, 1, 2000, pp. 28-49.

[19] U. Quasthoff, and H. Steinbring, "Diskurseinheiten im Mathematikunterricht" (Discourse units in mathematic lessons), Grundschule, 12, 2000, pp. 57-59. 
[20] G. Krummheuer, „Die empirisch begründete Herleitung des Begriffs der "Interaktionalen Nische mathematischer Denkentwickung (NMD)", (The empirically justified derivation of the term ,Interactional niche of the development of mathematical thinking") In B. Brandt, R. Vogel, and G. Krummheuer (Eds.), Die Projekte erStMaL und MaKreKi. Mathematikdidaktische Forschung am "Center for Individual Development and Adaptive Education" (IDeA) (Vol. 10, pp. 25-90). Waxmann, Münster, München [u.a.], 2011.

[21] A. Schröder, Interaktive Erzählfähigkeiten sprachentwicklungsgestörter Kinder: Eine vergleichende Analyse.(interactive narrative competencies of children with developmental language disorders) Südwestdeutscher Verl. für Hochschulschriften, Saarbrücken, 2010.

[22] A. Fritz, and G. Ricken, „Grundlagen des Förderkonzeptes 'Kalkulie'"'(Basics of the fostering concept 'Kalkulie'), In A. Fritz (Ed.), Handbuch Rechenschwäche. Lernwege, Schwierigkeiten und Hilfen bei Dyskalkulie (2nd ed.,) Beltz, Weinheim, 2009, pp. 374-395.

[23] H.Bauersfeld, (2002). Interaktion und Kommunikation. Grundschule, 3, 2002, pp. 10-14. 